\title{
Arsenic Speciation and Volatilization from Flooded Paddy Soils Amended with Different Organic Matters
}

\author{
Hai Huang, ${ }^{\dagger, \ddagger}$ Yan Jia, ${ }^{\dagger, \ddagger}$ Guo-Xin Sun, ${ }^{\dagger}$ and Yong-Guan Zhu* ${ }^{\dagger,}, \S$ \\ ${ }^{\dagger}$ Research Center for Eco-Environmental Sciences, Chinese Academy of Sciences, Beijing 100085, People’s Republic of China \\ ${ }^{\S}$ Key Laboratory of Urban Environment, Health, Institute of Urban Environment, Chinese Academy of Sciences, Xiamen 361021, \\ People's Republic of China
}

\section{Supporting Information}

ABSTRACT: Arsenic (As) methylation and volatilization in soil can be increased after organic matter (OM) amendment, though the factors influencing this are poorly understood. Herein we investigate how amended $\mathrm{OM}$ influences As speciation as well as how it alters microbial processes in soil and soil solution during As volatilization. Microcosm experiments were conducted on predried and fresh As contaminated paddy soils to investigate microbial mediated As speciation and volatilization under different $\mathrm{OM}$ amendment conditions.

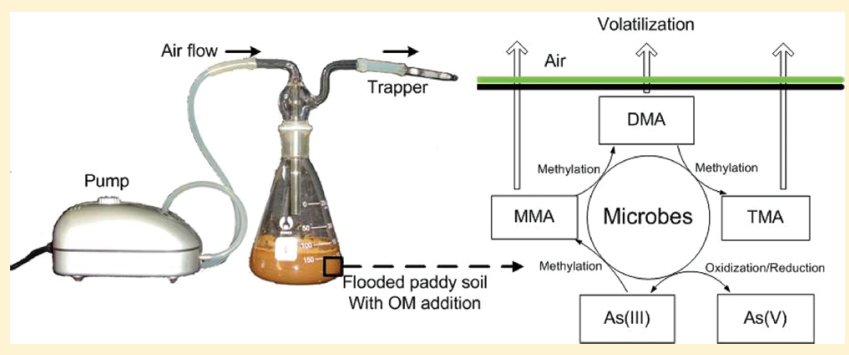
These experiments indicated that the microbes attached to OM did not significantly influence As volatilization. The arsine flux from the treatment amended with $10 \%$ clover (cloveramended treatment, CT) and dried distillers grain (DDG) (DDG-amended treatment, DT2) were significantly higher than the control. Trimethylarsine (TMAs) was the dominant species in arsine derived from CT, whereas the primary arsine species from DT2 was TMAs and arsine $\left(\mathrm{AsH}_{3}\right)$, followed by monomethylarsine $\left(\mathrm{MeAsH}_{2}\right)$. The predominant As species in the soil solutions of CT and DT2 were dimethylarsinic acid (DMAA) and As(V), respectively. OM addition increased the activities of arseniteoxidizing bacteria (harboring aroA-like genes), though they did not increase or even decrease the abundance of arsenite oxidizers. In contrast, the abundance of arsenate reducers (carrying the $\operatorname{ars} C$ gene) was increased by $\mathrm{OM}$ amendment; however, significant enhancement of activity of arsenate reducers was observed only in CT. Our results demonstrate that OM addition significantly increased As methylation and volatilization from the investigated paddy soil. The physiologically active bacteria capable of oxidization, reduction, and methylation of As coexisted and mediated the As speciation in soil and soil solution.

\section{INTRODUCTION}

Arsenic is a redox-active element that is ubiquitous in groundwater, sediments, and paddy field environments. ${ }^{1-3}$ The transformations of As species in soils usually involve oxidation, reduction, and methylation, all of which are commonly driven by microbes. ${ }^{4-6}$ The conversion between the more toxic As(III) and the less toxic As(V) cannot remove As from soils. However, arsenite methylation and subsequent volatilization is an important pathway for As removal from soils and sediments ${ }^{7}$ and is a process that is receiving increasing attention. $^{8-10}$

Currently, little is known about the bacterial methylation gene (arsM). This is despite the fact that volatilization of As from soil has been identified for more than half a century, and it is known that "volatilization capability" can be greatly enhanced by organic matter (OM) addition. ${ }^{11}$ Gao and Burau ${ }^{12}$ revealed that about $0.041-0.403 \%$ of As was volatilized from soil (spiked with sodium cacodylate at a final concentration of 10 $\mathrm{mg} / \mathrm{kg}$ ) amended with different amounts of cellulose during a 70-day incubation period. Edvantoro et al. ${ }^{13}$ reported that $8.3 \%$ of soil As was volatilized during 5 months incubation by treatment with $30 \%(\mathrm{w} / \mathrm{w})$ cow manure amendment under $75 \%$ field capacity condition. More recently, Mestrot et al. ${ }^{9}$ reported that $320 \mathrm{ng}$ of arsine was emitted in manure-amended and flooded paddy soil (100 g, with an As content of $24.2 \mathrm{mg} /$ $\mathrm{kg}$ ) in 3 weeks. However, the addition of OM does not always increase As volatilization. A previous report implied that the addition of glucose did not enhance the evolution of trimethylarsine (TMAs) under either aerobic or anaerobic conditions. $^{14}$

Different types of OM, such as cattle manure, rice straw, and urine, have been used as exogenous OM for soil amendment. ${ }^{9,10,13}$ In the present study, clover and dried distillers grain (DDG) are chosen for the following reasons: clover is widely used as green manure in farming, ${ }^{15,16}$ and as a main byproduct of brewing industry, DDG is abundantly available and is used as a growth medium for various microbes as well as to remediate contaminated environments. ${ }^{17,18}$ The addition of OM (as a nutrient) can stimulate the activity of indigenous microbes, which may strongly influence As speciation. Though microbes play critical roles in As volatilization, little attention has been

Received: October 13, 2011

Revised: January 17, 2012

Accepted: January 25, 2012

Published: January 25, 2012 
paid to the changes in bacterial abundance and relative functional genes after $\mathrm{OM}$ addition. Thus, this research is conducted to evaluate the influence of OM (clover and DDG) on As speciation and volatilization from paddy soil under laboratory conditions and to investigate the shifts in microbial abundance and activity of some functional genes ( $\operatorname{ars} C$ and aroA-like genes) in soils amended with different OM.

\section{MATERIALS AND METHODS}

Preparation of Organic Matters and Paddy Soil. Clover and DDG were used in this study as exogenous OM. Clover stems and leaves were collected, air-dried, and ground with a mortar and pestle to powder. DDG was oven-dried at $70{ }^{\circ} \mathrm{C}$ overnight and then ground as with the clover. A part of the ground DDG was sterilized at $121{ }^{\circ} \mathrm{C}$ for $30 \mathrm{~min}$ and redried at $70{ }^{\circ} \mathrm{C}$. Characteristics of clover and DDG are listed in Supporting Information Table S1.

Paddy soil was sampled from an arsenic-polluted field in Chenzhou, Hunan Province, China. One part of the sample was air-dried, sieved to pass a $2-\mathrm{mm}$ sieve, and kept in darkness until use. The rest of the soil sample was kept flooded to mimic the original field conditions. The soil's OM was $41.3 \pm 2.1 \mathrm{~g} /$ $\mathrm{kg}$, and As concentration was $77.3 \pm 5.0 \mathrm{mg} / \mathrm{kg}$.

Microcosm Experiments. Experiment 1 used dried paddy soil: $100 \mathrm{~g}$ of air-dried soil was weighed in conical flasks, 100 $\mathrm{mL}$ of deionized water was added to maintain flood conditions, and three treatments were performed with four replicates each: CTR1, control without DDG amendment; DT1, with $5 \mathrm{~g}$ of nonsterilized DDG; and SDT, with $5 \mathrm{~g}$ of sterilized DDG. The conical flask system and As trapping tubes for soil incubation and trapping of volatile As was conducted as described by Mestrot et al. ${ }^{9}$ with a little modification. Briefly, silica gel beads $(0.5-1.0 \mathrm{~mm})$ were impregnated with $10 \% \mathrm{AgNO}_{3}(\mathrm{w} / \mathrm{v})$ and then oven-dried overnight at $70{ }^{\circ} \mathrm{C}$. For trapping volatile As, tubes containing silver nitrate-impregnated silica gel (Chemotrap) were connected to the conical flask incubation system. The headspace air (containing volatile As) was refreshed by pumping air, which was filtered by a trapping tube to prevent As contamination derived from the ambient environment, into the headspace at a flow rate of $40 \mathrm{~mL} / \mathrm{min}$. The air outflow from the microcosms was trapped by the Chemo-trap, and the volatilized As was stabilized in the $\mathrm{AgNO}_{3}$-treated silica gel. The conical flasks were repeatedly weighed over time, deionized water was added if necessary to maintain the water content, and trapping tubes were replaced weekly with new ones. This experiment lasted for 63 days (9 weeks). The quantity and species of volatile As were determined by eluting the As bound to the silica gel in the trapping tube by extraction in diluted $\mathrm{HNO}_{3}$ and $\mathrm{H}_{2} \mathrm{O}_{2}$ via a microwave digestion system (Mars II, CEM, America). Hydrogen peroxide was used to oxidize arsenite to arsenate, since both trimethylarsine oxide (TMAO) and As(III) showed similar retention times in anionexchange chromatograma. ${ }^{9}$ Further details of the procedures and validation of the elution method can be found in Supporting Information Figure S1 and Table S2.

In order to test the As volatilization ability of clover and DDG in fresh paddy soil, the second microcosm experiment (experiment 2) was set up as follows: $100 \mathrm{~g}$ of fresh soil (wet weight, moisture content 52.3\%) was amended with $5.0 \mathrm{~g}$ of clover (CT) or nonsterilized DDG (DT2) in the conical flask system and then mixed homogenously before being flooded with $50 \mathrm{~mL}$ of deionized water. A treatment without any addition of exogenous OM was used as a control (CTR2). Each treatment was run with four replicates, giving a total of 12 experimental units. Arsines were trapped cumulatively over a 30-day period in this experiment. The trapping and elution of volatile As was the same as described in the first microcosm experiment. At the termination of this experiment, the surface water and slurry were homogenized and then collected by centrifugation of the suspension at $5000 \mathrm{~g}$ for $5 \mathrm{~min}$ and filtered $(0.45 \mu \mathrm{m})$ into a $10-\mathrm{mL}$ tube. The soil solution was digested by $1 \% \mathrm{HNO}_{3}$ before As analysis to remove OM (details and validation of the digestion method are presented in Supporting Information Table S3). Since both TMAO and As(III) show the same retention time in anion-exchange chromatograms here, to evaluate the concentration of TMAO in soil solution, a part of the digested soil solution of each treatment was further treated with $\mathrm{H}_{2} \mathrm{O}_{2}$. The pellet was stored at $-80{ }^{\circ} \mathrm{C}$ for microbial DNA, RNA, and soil As speciation extraction.

Extraction of Arsenic in Paddy Soil. Fresh soil was used for As species extraction, as is generally recommended. ${ }^{19}$ As $(\mathrm{V})$ and As(III) speciation in paddy soil were assessed by $1 \mathrm{M}$ orthophosphoric acid and $0.5 \mathrm{M}$ ascorbic acid via microwaveassisted extraction. ${ }^{20}$ After microwave digestion, the suspensions were centrifuged at $5000 \mathrm{~g}$ for $5 \mathrm{~min}$ and then filtered through $0.45-\mu \mathrm{m}$ filters. The filtered samples were stored at $-20{ }^{\circ} \mathrm{C}$ before analysis.

Characterization of Organic Matters, Soil, and Soil Solution. The $\mathrm{C}$ and $\mathrm{N}$ content of $\mathrm{OM}$ were detected on an element analyzer (Vario EL III, Elementar, Germany). The protein content of $\mathrm{OM}$ was calculated from the total $\mathrm{N}$ by use of a factor of 6.25. The starch in the OM was hydrolyzed to glucose and then measured with Fehling's reagent. For the cellulose content of clover and DDG, the OM was digested in $0.5 \mathrm{M} \mathrm{H}_{2} \mathrm{SO}_{4}$ and $20 \mathrm{~g} / \mathrm{L}$ cetyltriethylammnonium bromide mixture in a boiling water bath, and the residue was then ovendried, weighed, and finally defined as cellulose. The OM content of soil was measured by the $\mathrm{K}_{2} \mathrm{Cr}_{2} \mathrm{O}_{7}$ oxidationreduction titration method. The $\mathrm{pH}$ of soil solution was measured on a FiveEasy $\mathrm{pH}$ meter (Mettler Toledo, Swiss). The concentration of ferrous ion $[\mathrm{Fe}(\mathrm{II})]$ in soil solution was measured by 1,10-phenanthroline spectrophotometry at 530 $\mathrm{nm}$. Total $\mathrm{Fe}, \mathrm{Mn}, \mathrm{K}$, and $\mathrm{P}$ were determined by an inductively coupled plasma optical emission spectrometer (ICP-OES, Optima 2000 DV, Perkin-Elmer, USA). Total arsenic As(Tot) concentration was measured by inductively coupled plasma mass spectrometry (ICP-MS), and As species were analyzed by HPLC-ICP-MS (Agilent 7500, Agilent Technologies, USA). Dissolved organic carbon (DOC) was determined by a total organic carbon (TOC) analyzer (Liquic TOC, Elementar, Germany).

DNA/RNA Extraction, 16S rDNA/rRNA, aroA-like and arsC DNA/mRNA Quantification. Soil DNA was prepared with a FastDNA SPIN kit (BIO101, Vista) following the manufacturer's instructions. The DNA was dissolved in $100 \mu \mathrm{L}$ of sterilized deionized water and stored at $-20{ }^{\circ} \mathrm{C}$ before use. For soil RNA extraction, about $0.25 \mathrm{~g}$ (dried weight) of fresh soil was extracted in a phosphate buffer. The residual DNA in RNA solution was eliminated by recombinant DNase I (TaKaRa) following the manufacturer's instructions. PrimeScript II first strand cDNA synthesis kit (TaKaRa) was used for reverse transcription of microbial $16 \mathrm{~S}$ rRNA and aroA-like and ars $C$ mRNA. Quantification of $16 \mathrm{~S} \mathrm{rDNA} / \mathrm{rRNA}$ and aroA-like and $\operatorname{arsC} \mathrm{DNA} / \mathrm{mRNA}$ were performed on an iQ5 thermocycler (Bio-Rad). The details for RNA extraction and purification and for quantification of $16 \mathrm{~S} \mathrm{rDNA} / \mathrm{rRNA}$ and 
aroA-like and arsC DNA/mRNA are provided in Supporting Information.

Statistical Analysis. All statistical analyses were performed with the use of SPSS 13.0 software (SPSS Inc., Chicago, IL). One-sample $t$-test was used to measure significant differences between treatments. A $p$-value $<0.05$ was judged to be statistically significant.

\section{RESULTS}

Arsine Speciation and Volatilization. For experiment 1, the addition of DDG significantly enhanced As volatilization from the paddy soil (Figure 1). Arsenic volatilization flux from

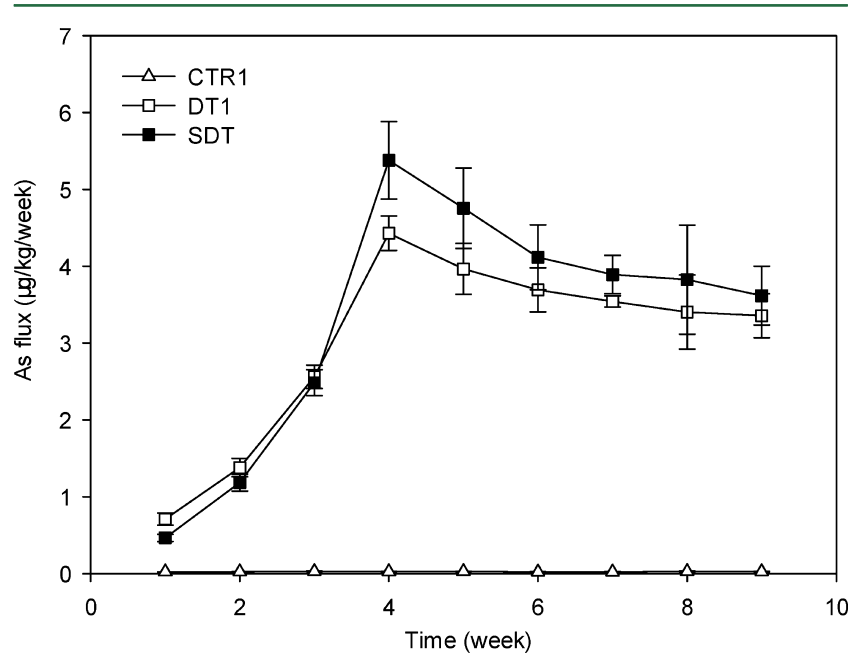

Figure 1. Arsines volatilization from paddy soil amended with sterilized and nonsterilized DDG in experiment 1. CTR1, control treatment (without DDG amendment); DT1, treatment amended with nonsterilized DDG; SDT, treatment amended with sterilized DDG.

the treatments amended with sterilized or nonsterilized DDG was hundreds of times higher than the control (CTR1), of which the arsenic flux was comparatively negligible. For treatments with DDG addition, the arsine flux increased with time until a maximal flux of $4.4-5.3 \mu \mathrm{g} / \mathrm{kg} /$ week at the fourth week was reached, before the flux slowly decreased to 3.4-3.6 $\mu \mathrm{g} / \mathrm{kg} /$ week at the ninth week (Figure 1). There was no significant difference in As volatilization fluxes between the treatments with sterilized DDG and nonsterilized DDG. The predominant arsine species was TMAs, followed by small amounts of $\mathrm{AsH}_{3}$ and $\mathrm{Me}_{2} \mathrm{AsH}$ (Supporting Information Figure S2).

For experiment 2 , very little $(0.07 \mu \mathrm{g} / \mathrm{kg} /$ month $)$ volatile As was detected in CTR2, while the treatment with DDG addition showed a flux of $9.8 \mu \mathrm{g} / \mathrm{kg} / \mathrm{month}$, which was more than 2 times higher than that of the treatment with clover amendment (CT) $(4.6 \mu \mathrm{g} / \mathrm{kg} / \mathrm{month})$ (Figure 2). Overall, about $0.006-$ $0.013 \%$ of total soil As or 228-490 ng of As was volatilized in treatments with $\mathrm{OM}$ addition in 30 days. The dominant arsine species in the CT was TMAs, while $\mathrm{AsH}_{3}$ and TMAs were the main arsines for DT2, followed by $\mathrm{MeAsH}_{2}$ (Supporting Information Figure S3).

Arsenic Speciation in Soil and Soil Solution. Speciation analysis of the soil from experiment 2 showed that inorganic As $[\mathrm{As}(\mathrm{III})$ and $\mathrm{As}(\mathrm{V})]$ were the dominant species in all treatments (Table 1). OM amendment slightly increased (but not at a significant level) the percentage of As(III) in the soil.

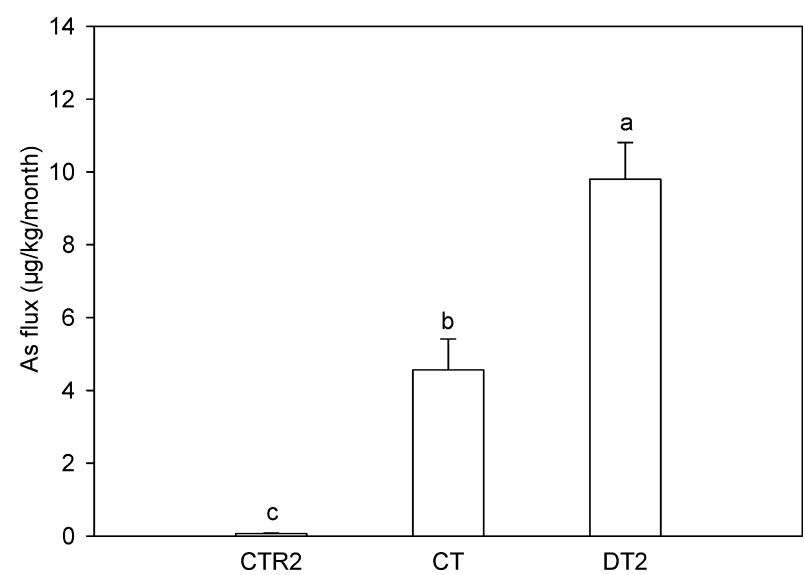

Figure 2. Arsines volatilization from paddy soil amended with different $\mathrm{OM}$ in experiment 2. CTR2, control treatment (without organic matter amendment); CT, treatment amended with clover; DT2, treatment amended with nonsterilized DDG.

The percentage of As(III) in the soil from CT and DT2 were a little higher than As(V), but As(III) was apparently lower than As $(\mathrm{V})$ in soil from CTR2 (Table 1).

Results from the soil solutions collected in experiment 2 showed that $\mathrm{OM}$ addition significantly increased As release to the soil solutions (Table 1). The predominant species in the soil solution of CTR2 and DT2 were As(V) (accounting for $91.8 \%$ and $58.3 \%$ of total As in aqueous phase, respectively), while dimethylarsinic acid (DMAA) was the predominant species in the soil solution of CT (accounting for $91.8 \%$ of total As in aqueous phase). The concentration of TMAO in the soil solution of each treatment was below the detection limit $(1 \mu \mathrm{g} /$ L). No methylated As was detected in the soil solution of CTR2, and more As species, such as As(III), As(V), monomethylarsonic acid (MMAA), and DMAA, were detected in the soil solutions of CT and DT2. In addition, an unknown As species was detected in the soil solution of the four replicates of DT2, which accounted for about $6.6 \%$ of total As in the aqueous phase (Supporting Information Figure S4; Table 1).

Abundance of 16S rDNA/rRNA and aroA-like and arsC DNA/mRNA. Bacterial abundance (indicated by $16 \mathrm{~S}$ rDNA copy number $)$ in DT2 $\left(8.5 \times 10^{8} / \mathrm{g}\right.$ dry soil $)$ was more than 3 times higher than in other treatments $\left(2.6 \times 10^{8} / \mathrm{g}\right.$ dry soil for CTR2 and $2.3 \times 10^{8} / \mathrm{g}$ dry soil for CT). Clover addition did not increase the bacterial abundance, but it enhanced total bacterial activity by several hundred times (indicated by the $16 \mathrm{~S}$ rRNA copy numbers) compared to CTR2 (Figure 3a). The $16 \mathrm{~S}$ rRNA copy numbers ranged from $(0.09$ to 28.2$) \times 10^{8} / \mathrm{g}$, giving a ratio of $16 \mathrm{~S}$ rRNA/16S rDNA between 0.03 and 5.2. DT2 showed the highest $16 \mathrm{~S}$ rRNA and 16S rDNA copy numbers among the three treatments (Figure $3 \mathrm{a}$ ).

The aroA-like genes copy number of CTR2 was about $4.0 \times$ $10^{7} / \mathrm{g}$ dry soil, which increased slightly (though not at a significant level) to $5.0 \times 10^{7} / \mathrm{g}$ dry soil in the treatment with DDG addition. In contrast, the addition of clover decreased aroA-like genes copy number to $1.6 \times 10^{7} / \mathrm{g}$ dry soil (Figure $3 b)$. Nevertheless, the mRNA copies of aroA-like genes were significantly enhanced with $\mathrm{OM}$ addition (Figure $3 \mathrm{~b}$ ). The aroA-like mRNA copy numbers ranged from $4.46 \times 10^{5} / \mathrm{g}$ dry soil to $2.33 \times 10^{6} / \mathrm{g}$ dry soil, 1 order of magnitude less than aroA-like genes copy numbers, resulting in a ratio of aro $A$-like $\mathrm{mRNA}$ /aroA-like DNA ranging from 0.01 to 0.07 (Figure $3 \mathrm{~b}$ ). 
Table 1. Arsenic Speciation in Soil and Soil Solution after Soil Incubation

\begin{tabular}{|c|c|c|c|c|c|c|c|c|c|c|}
\hline \multirow[b]{2}{*}{ treatment $^{c}$} & \multicolumn{6}{|c|}{ arsenic species in soil solution $(\mu \mathrm{g} / \mathrm{L})^{a}$} & \multicolumn{4}{|c|}{ arsenic species in soil $(\%)^{b}$} \\
\hline & As(III) & $\operatorname{As}(V)$ & MMAA & DMAA & unknown $^{d}$ & total $\mathrm{As}^{e}$ & $\mathrm{As}(\mathrm{III})$ & $\operatorname{As}(\mathrm{V})$ & others $^{f}$ & recovery $^{g}$ \\
\hline CTR2 & $1.8 \pm 0.5$ & $20.3 \pm 5.4$ & $h$ & $h$ & $h$ & $22.1 \pm 5.0$ & $39.7 \pm 0.8$ & $51.7 \pm 2.9$ & $8.7 \pm 1.4$ & 87.1 \\
\hline $\mathrm{CT}$ & $63.5 \pm 15.2$ & $73.0 \pm 6.5$ & $13.5 \pm 1.6$ & $339 \pm 18$ & $h$ & $488 \pm 26$ & $46.1 \pm 4.5$ & $40.8 \pm 0.4$ & $13.2 \pm 6.7$ & 84.0 \\
\hline DT2 & $23.4 \pm 2.6$ & $219 \pm 33$ & $64.8 \pm 12.3$ & $43.0 \pm 11.3$ & $25.2 \pm 6.5$ & $375 \pm 58$ & $48.7 \pm 4.4$ & $41.2 \pm 8.4$ & $10.1 \pm 1.9$ & 75.3 \\
\hline
\end{tabular}

${ }^{a}$ The concentration of TMAO in soil solution of each treatment was below the detection limit so we ignored it. ${ }^{b}$ Relative abundance of As species was calculated by comparing each As species to the sum of all As species in paddy soil. ${ }^{c} \mathrm{CTR} 2$, control treatment (without OM amendment); CT, treatment amended with clover; DT2, treatment amended with nonsterilized DDG. ${ }^{d}$ Unknown: Unknown As species. ${ }^{e}$ Total As was the sum of As species in soil solution. ${ }^{f}$ Others: Arsenic species excluded As(III) and As $(\mathrm{V}) .{ }^{g}$ Recovery was calculated by comparing the sum of each As species with total As content $(77.3 \pm 5 \mathrm{mg} / \mathrm{kg})$ of the paddy soil. ${ }^{h}$ Not detected.

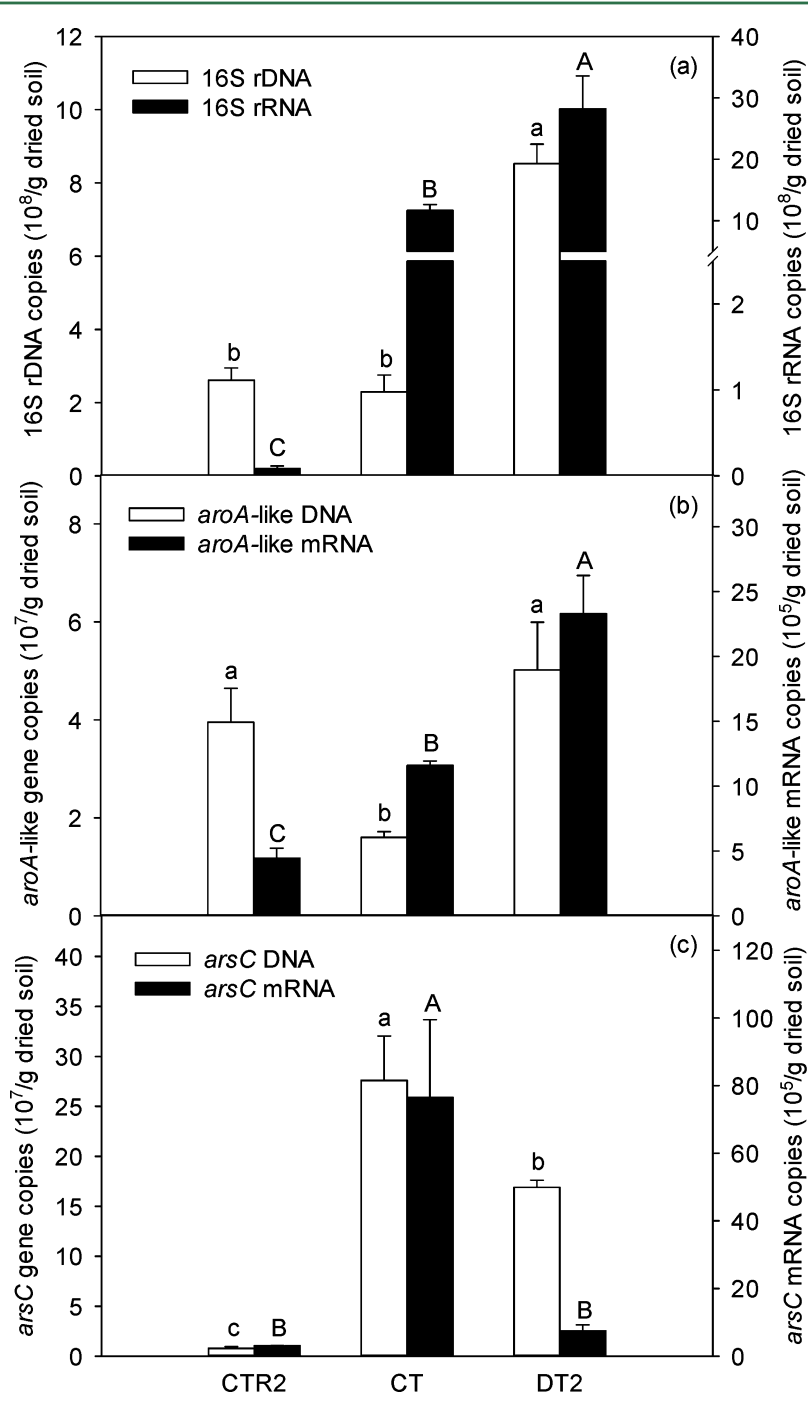

Figure 3. Abundance of (a) $16 \mathrm{~S}$ rDNA/rRNA, (b) aroA-like DNA/ mRNA, and (c) arsC DNA/mRNA in paddy soil amended with different OM. The different lowercase/capital letters above the open/ solid columns indicate significant differences $(p<0.05)$ between them. CTR2, control treatment (without OM amendment); CT, treatment amended with clover; DT2, treatment amended with nonsterilized DDG.

The ars $C$ gene copy numbers were about 2 orders of magnitude higher than ars $C$ mRNA copy numbers (ars $C$ $\mathrm{mRNA} /$ arsC DNA ratio ranged from 0.004 to 0.04) (Figure $3 \mathrm{c}$ ). Specifically, the $\operatorname{ars} C$ gene copy numbers ranged from 0.78 $\times 10^{7} / \mathrm{g}$ dry soil to $2.8 \times 10^{8} / \mathrm{g}$ dry soil, and that of $\mathrm{mRNA}$ copy numbers lay between $3.0 \times 10^{5} / \mathrm{g}$ dry soil and $7.7 \times 10^{6} / \mathrm{g}$ dry soil. DDG addition significantly increased ars $C$ gene copy number but did not change the mRNA copy number significantly. Clover addition apparently increased both the ars $C$ gene and mRNA copy numbers (Figure $3 \mathrm{c}$ ).

\section{DISCUSSION}

Arsenic Volatilization. Both sterilized and nonsterilized DDG addition showed similar arsine flux that was hundreds of times greater than the control (CTR1), indicating the potential of $\mathrm{OM}$ addition in enhancing As volatilization, possibly through the stimulation of indigenous microbial activity ${ }^{13}$ rather than inoculation of microbes attached to OM (here DDG). Arsine fluxes were significantly impacted by OM types, as shown in this study and a previous report. ${ }^{10}$ This may be due to the different microbial communities presented in the treatments with different $\mathrm{OM}$ additions. ${ }^{14}$ Interestingly, air-dried soil amended with 5\% DDG (sterilized or nonsterilized) exhibited similar arsine flux (about 9.1-9.8 $\mu \mathrm{g} / \mathrm{kg} /$ month) with fresh soil amended with $10 \%$ of DDG (nonsterilized), though the arsine speciation was different (Supporting Information Figures S2 and S3). However, previous studies have indicated that an increase in OM addition does not always result in an increase of As volatilization. ${ }^{8}$ Arsine fluxes from CT and DT2 were several times higher than those of Bangladesh paddy soils amended with $10 \%$ cow dung or rice straw in a previous study. ${ }^{10}$ This was due in part to relatively high As concentration in soil solution in the present study, since the concentration was positively correlated with As flux. ${ }^{10,13}$ Another possible explanation is that there were more As methylaters in the paddy soil of this study compared to Bangladesh's; however, further work on the arsM gene is needed to confirm this explanation.

As shown above, arsines derived from DT2 in experiment 2 were mainly TMAs and $\mathrm{AsH}_{3}$, followed by $\mathrm{MeAsH}_{2}$ (Supporting Information Figure S3), which were different from that derived from CT in experiment 2 (Supporting Information Figure S3), as well as arsines produced by the soil amended with DDG in experiment 1 (Supporting Information Figure S2). It is known that As(III) methylation is a strictly biological process and driven by microbial activity. ${ }^{14}$ Therefore, these observations were probably again a result of the changes in soil microbial communities, as different bacterial species could produce various arsines. ${ }^{21,22}$

DT2 exhibited a higher As flux, though lower As concentration in soil solution, compared to CT (Figure 2 and Table 1). These results differ from those of a previous study where As concentration in soil-water was positively correlated with total arsine and methylarsines. ${ }^{10}$ This inconsistency indicates that, in addition to the amount of bioavailable As, other factors like microbial activities, may also play important roles in As volatilization. ${ }^{23}$ It is worth noting that both bacterial 
abundance and activity (indicated by $16 \mathrm{~S}$ rDNA and $16 \mathrm{~S}$ rRNA copy number, respectively) of DT2 were significantly higher than those of CT (Figure 3a). There was no clear relationship between As speciation in soil solution and arsine species, which was consistent with the finding of Mestrot et al. ${ }^{10}$

Arsenic Speciation in Soil and Soil Solution. The accepted prevailing hypothesis is that inorganic As is transformed to TMAs through the "Challenger pathway", ${ }^{24}$ and the rate-limiting steps of the pathway under specific conditions may be different. For example, it has been suggested that the initial conversion of inorganic As to $\mathrm{MMAA}^{10}$ or reduction of MMAA(V) to MMAA(III) ${ }^{25}$ may be the rate-limiting step in the metabolism of inorganic As, while Kenyon et al. ${ }^{26}$ pointed out that the reduction of $\mathrm{As}(\mathrm{V})$ to $\mathrm{As}(\mathrm{III})$ may also be a ratelimiting step. In the present study, we found that the As flux of CT was more than 2 times lower than that of DT2, while DMAA in the soil solution of CT was several times higher than that in DT2 (Table 1), indicating that the transformation from DMAA to TMAs may be the rate-limiting step, which is consistent with a previous finding. ${ }^{27}$ The higher concentration of As(III) in the soil solution of CT than the other treatments may result from a higher abundance and activity of arsenatereducing bacteria harboring the $\operatorname{ars} C$ gene, as shown in Figure $3 c$.

DT2 exhibited relatively higher arsine fluxes, though with lower As(III) (the As "methylation substrate") concentration in soil solution, compared with CT. Therefore, we propose that the relatively lower As(III) concentration (compared with CT) or the reduction of As(V) to As(III) was not the rate-limiting factor for As methylation. Since As(III) was the dominant species in the soil from DT2 (Table 1) and because As(V) is generally less labile than As(III) in most soils and sediments, ${ }^{28}$ the higher $\mathrm{As}(\mathrm{V})$ concentration in the soil solution of DT2 probably resulted from the oxidization of As(III) in aqueous phase. Compared to the other two treatments, the much higher $\mathrm{Fe}(\mathrm{II})$ in the soil solution of DT2 (Supporting Information, Table S4) indicated that the addition of OM led to much more reducing conditions. Under these conditions, we deduce that arsenite-oxidizing bacteria could have contributed to As(III) oxidization, though some dissolved organic matters (DOM) could have contributed additionally. ${ }^{29}$ To confirm this speculation, we evaluated the activities of arsenic oxidization/ reduction bacteria by quantifying the mRNA of aroA-like and ars $C$ genes. These results clearly show that the bacteria in DT2 exhibited high As oxidization but low reduction activities (Figure $3 b, c)$, which accounts for As $(V)$ accumulation in the soil solution. An alternative explanation was that since DDG amendment led to a more strongly reducing environment where more iron oxides were reductively dissolving, more As $(V)$ that bound to iron oxides could have been released compared to the CT. The concentration of $\mathrm{As}(\mathrm{V})$ was much higher in DT2 than CT, probably because clover amendment led to much higher abundance and activity for arsenatereducers and lower for arsenite-oxidizers (Figure 3b,c). Interestingly, in the soil solution of DT2 we detected an unknown As species peak between DMAA and MMAA, which is speculated to be an As(III)-thiolate complex. ${ }^{30}$

Abiotic Factors Affecting Arsenic Methylation in Soil. The addition of OM profoundly altered the physical-chemical properties of paddy soil and soil solution in the investigated microcosm systems (Supporting Information, Table S4). Though As methylation is a strictly biological process, it can also be affected by abiotic factors, such as temperature, $\mathrm{pH}$, and culture substrates. ${ }^{31}$ The $\mathrm{pH}$ of soil solution dropped from 8.7 to 8.3 and 8.1 for CT and DT2, respectively (Supporting Information, Table S4). These decreases in $\mathrm{pH}$ may enhance microbial-mediated As volatilization, as the optimum $\mathrm{pH}$ for TMAs production is around 5.0-6.0.31,32 Huysmans and Frankenberger $^{31}$ have shown that even a slight decrease in $\mathrm{pH}$ from 8.5 to 8.0 can increase the production of TMAs. The significant increase in $\mathrm{Fe}(\mathrm{II})$ in soil solution may also favor As methylation. ${ }^{33}$ In addition, the high concentration of diverse DOC in the treatments with OM addition on one hand may enhance As bioavailability for microbes capable of As methylation (Table 1); on the other hand, DOC of different derivations could serve as nutrients for the growth of various microbes including As methylaters, and both factors would be conducive to As volatilization. On the basis of the above discussion, we conclude that the alteration of physicalchemical properties of paddy soil and soil solution may be an important way through which $\mathrm{OM}$ can influence As methylation and volatilization.

The results from the present study demonstrate that both clover and DGG addition significantly enhanced As methylation and volatilization, while DDG was much more efficient. In addition, we report for the first time the successful quantification of aroA-like genes and their mRNA from Ascontaminated paddy soil. The results indicate that physiologically active bacteria capable of oxidization, reduction, and methylation of As coexisted in the investigated systems. Organic matter addition significantly changed not only biotic factors (such as bacterial abundances and their activities) but also abiotic factors (such as bioavailability of As and $\mathrm{pH}$ ), all of which would influence As methylation and volatilization.

\section{ASSOCIATED CONTENT}

\section{S Supporting Information}

Additional text, four figures, and four tables giving characterizations of clover, DDG, and soil solution from the three treatments in experiment 2; details of validation of the microwave digestion method; results of arsenic speciation in arsine and soil solution; RNA extraction and purification; and details on quantification of $16 \mathrm{~S} \mathrm{rDNA} / \mathrm{rRNA}$ and aroA-like and ars $C$ DNA/mRNA. This material is available free of charge via the Internet at http://pubs.acs.org/.

\section{AUTHOR INFORMATION}

\section{Corresponding Author}

*E-mail: ygzhu@rcees.ac.cn.

\section{Author Contributions}

These authors contributed equally to this work.

\section{Notes}

The authors declare no competing financial interest.

\section{ACKNOWLEDGMENTS}

This work is financially supported by Natural Science Foundation of China (41090284 and 41090282) and the Chinese Academy of Sciences (KZCX2-YW-Q02-06). We thank Xixiang Yin and Peng Bao in the Research Center for Eco-Environmental Sciences, Chinese Academy of Sciences, for their constructive suggestions during experiments. We also thank Dr. Hans Peter in Norges Geotekniske Institutt for kindly proofreading the manuscript. 


\section{REFERENCES}

(1) Rahman, M. M.; Naidu, R.; Bhattacharya, P. Arsenic contamination in groundwater in the Southeast Asia region. Environ. Geochem. Health. 2009, 31, 9-21.

(2) Polizzotto, M. L.; Kocar, B. D.; Benner, S. G.; Sampson, M.; Fendorf, S. Near-surface wetland sediments as a source of arsenic release to ground water in Asia. Nature 2008, 454 (7203), 505-508.

(3) Khan, M. A.; Stroud, J. L.; Zhu, Y. G.; McGrath, S. P.; Zhao, F. J. Arsenic bioavailability to rice is elevated in Bangladeshi paddy soils. Environ. Sci. Technol. 2010, 44 (22), 8515-8521.

(4) Liao, V. H. C.; Chu, Y. J.; Su, Y. C.; Hsiao, S. Y.; Wei, C. C.; Liu, C. W.; Liao, C. M.; Shen, W. C.; Chang, F. J. Arsenite-oxidizing and arsenate-reducing bacteria associated with arsenic-rich groundwater in Taiwan. J. Contam. Hydrol. 2011, 123 (1-2), 20-29.

(5) Bentley, R.; Chasteen, T. G. Microbial methylation of metalloids: arsenic, antimony, and bismuth. Microbiol. Mol. Biol. Rev. 2002, 66 (2), 250-271.

(6) Rhine, E. D.; Garcia-Dominguez, E.; Phelps, C. D.; Young, L. Y. Environmental microbes can speciate and cycle arsenic. Environ. Sci. Technol. 2005, 39 (24), 9569-9573.

(7) Woolson, E. A. Fate of arsenicals in different environmental substrates. Environ. Health. Perspect. 1977, 19, 73-81.

(8) Mohapatra, D.; Mishra, D.; Chaudhury, G. R.; Das, R. P. Removal of arsenic from arsenic rich sludge by volatilization using anaerobic microorganisms treated with cow dung. Soil Sediment Contam. 2008, 17 (3), 301-311.

(9) Mestrot, A.; Uroic, M. K.; Plantevin, T.; Islam, M. R.; Krupp, E. M.; Feldmann, J.; Meharg, A. A. Quantitative and qualitative trapping of arsines deployed to assess loss of volatile arsenic from paddy soil. Environ. Sci. Technol. 2009, 43 (21), 8270-8275.

(10) Mestrot, A.; Feldmann, J.; Krupp, E. M.; Hossain, M. S.; Roman-Ross, G.; Meharg, A. A. Field fluxes and speciation of arsines emanating from soils. Environ. Sci. Technol. 2011, 45 (5), 1798-1804.

(11) Akins, M. B.; Lewis, R. J. Chemical distribution and gaseous evolution of As-74 added to soils as DSMA- ${ }^{74}$ As. Soil. Sci. Soc. Am. J. 1976, 40 (5), 655-658.

(12) Gao, S.; Burau, R. G. Environmental factors affecting rates of arsine evolution from and mineralization of arsenicals in soil. J. Environ. Qual. 1997, 26 (3), 753-763.

(13) Edvantoro, B. B.; Naidu, R.; Megharaj, M.; Merrington, G.; Singleton, I. Microbial formation of volatile arsenic in cattle dip site soils contaminated with arsenic and DDT. Appl. Soil. Ecol. 2004, 25 (3), 207-217.

(14) Turpeinen, R.; Pantsar-Kallio, M.; Kairesalo, T. Role of microbes in controlling the speciation of arsenic and production of arsines in contaminated soils. Sci. Total Environ. 2002, 285 (1-3), $133-145$.

(15) Ross, S. M.; King, J. R.; Izaurralde, R. C.; O’Donovan, J. T. The green manure value of seven clover species grown as annual crops on low and high fertility temperate soils. Can. J. Plant Sci. 2009, 89 (3), 465-476.

(16) Elfstrand, S.; Bath, B.; Martensson, A. Influence of various forms of green manure amendment on soil microbial community composition, enzyme activity and nutrient levels in leek. Appl. Soil. Ecol. 2007, 36 (1), 70-82.

(17) Agamuthu, P.; Abioye, O. P.; Abdul Aziz, A. Phytoremediation of soil contaminated with used lubricating oil using Jatropha curcas. J. Hazard. Mater. 2010, 179 (1-3), 891-894.

(18) Aliyu, S.; Bala, M. Brewer's spent grain: A review of its potentials and applications. Afr. J. Biotechnol. 2011, 10 (3), 324-331.

(19) Szakova, J.; Tlustos, P.; Goessler, W.; Frkova, Z.; Najmanova, J. Mobility of arsenic and its compounds in soil and soil solution: the effect of soil pretreatment and extraction methods. J. Hazard. Mater. 2009, 172 (2-3), 1244-1251.

(20) Giral, M.; Zagury, G. J.; Deschenes, L.; Blouin, J. P. Comparison of four extraction procedures to assess arsenate and arsenite species in contaminated soils. Environ. Pollut. 2010, 158 (5), 1890-1898.

(21) Shariatpanahi, M.; Anderson, A. C.; Abdelghani, A. A.; Englande, A. J.; Hughes, J.; Wilkinson, R. F. Biotransformation of the pesticide sodium arsenate. J. Environ. Sci. Health B 1981, 16 (1), $35-47$.

(22) Cheng, C. N.; Focht, D. D. Production of arsine and methylarsines in soil and in culture. Appl. Environ. Microb. 1979, 38 (3), 494-498.

(23) Sanford, R. A.; Klein, D. A. Environmental bioremediation for organometallic compounds: microbial growth and arsenic volatilization from soil and retorted shale. Appl. Organomet. Chem. 1988, 2 (2), 159-169.

(24) Challenger, F. Biological Methylation. Chem. Rev. 1945, 36 (3), 315-361.

(25) Zakharyan, R. A.; Aposhian, H. V. Enzymatic reduction of arsenic compounds in mammalian systems: the rate-limiting enzyme of rabbit liver arsenic biotransformation is MMA(V) reductase. Chem. Res. Toxicol. 1999, 12 (12), 1278-1283.

(26) Kenyon, E. M.; Del Razo, L. M.; Hughes, M. F. Tissue distribution and urinary excretion of inorganic arsenic and its methylated metabolites in mice following acute oral administration of arsenate. Toxicol. Sci. 2005, 85 (1), 468-475.

(27) Yin, X. X.; Chen, J.; Qin, J.; Sun, G. X.; Rosen, B.; Zhu, Y. G. Biotransformation and volatilization of arsenic by three photosynthetic cyanobacteria. Plant Physiol. 2011, 156 (3), 1631-1638.

(28) Gupta, S. K.; Chen, K. Y. Arsenic removal by adsorption. J. Water. Pollut. Contr. Fed. 1978, 50 (3), 493-506.

(29) Bauer, M.; Blodau, C. Mobilization of arsenic by dissolved organic matter from iron oxides, soils and sediments. Sci. Total Environ. 2006, 354 (2-3), 179-190.

(30) Huang, J. H.; Fecher, P.; Ilgen, G.; Hu, K. N.; Yang, J. Speciation of arsenite and arsenate in rice grain-verification of nitric acid based extraction method and mass sample survey. Food Chem. 2011, 130 (2), $453-459$.

(31) Huysmans, K. D.; Frankenberger, W. T. Evolution of trimethylarsine by a Penicillium $s p$. isolated from agricultural evaporation pond water. Sci. Total Environ. 1991, 105, 13-28.

(32) Cox, D. P.; Alexande, M. Effect of phosphate and other anions on trimethylarsine formation by Candida humicola. Appl. Microbiol. 1973, 25 (3), 408-413.

(33) De Kimpe, J.; Cornelis, R.; Vanholder, R. In vitro methylation of arsenite by rabbit liver cytosol: effect of metal ions, metal chelating agents, methyltransferase inhibitors and uremic toxins. Drug Chem. Toxicol. 1999, 22 (4), 613-628. 